\title{
Paracoccidioidomycosis in a western Brazilian Amazon State: Clinical-epidemiologic profile and spatial distribution of the disease
}

\author{
Gabriel de Deus Vieira ${ }^{[1]}$, Thaianne da Cunha Alves ${ }^{[1]}$, Sônia Maria Dias de Lima ${ }^{[1],[2],}$ \\ Luís Marcelo Aranha Camargo ${ }^{[1],[3]}$ and Camila Maciel de Sousa ${ }^{[1]}$
}

[1]. Departamento de Medicina, Faculdade São Lucas, Porto Velho, RO. [2]. Coordenação do Programa de Controle da Paracoccidioidomicose, Agência Estadual de Vigilância em Saúde, Porto Velho, RO. [3]. Instituto de Ciências Biomédicas 5, Universidade de São Paulo, Monte Negro, RO.

\begin{abstract}
Introduction: Paracoccidioidomycosis (PCM) is a systemic infection caused by the fungus Paracoccidioides brasiliensis. PCM is considered one of the most important systemic mycoses in Latin America. Methods: This is a clinical, epidemiological, retrospective, quantitative study of PCM cases in patients attending the National Health Service in the State of Rondônia in 1997-2012. The examined variables included sex, age group, year of diagnosis, education level, profession, place of residence, diagnostic test, prior treatment, medication used, comorbidities and case progress. Results: During the study period, 2,163 PCM cases were registered in Rondônia, and the mean annual incidence was 9.4/100,000 people. The municipalities with the highest rates were located in the southeastern region of Rondônia, and the towns of Pimenteiras do Oeste and Espigão do Oeste had the highest rates in the state, which were 39.1/100,000 and 37.4/100,000 people, respectively. Among all cases, $90.2 \%$ and $9.8 \%$ were observed in men and women, respectively, and most cases $(58.2 \%)$ were observed in patients aged between 40 and 59 years. Itraconazole was used to treat $91.6 \%(1,771)$ of cases, followed by sulfamethoxazole in combination with trimethoprim (4.4\% [85] of cases). One hundred thirty-one (6\%) patients died. Conclusions: The State of Rondônia has a high incidence of PCM, and the municipalities in the southeastern region of the state were found to have the highest incidence rates of this disease. Our findings suggest that Rondônia is the state in the northern region with the highest mortality rate for PCM.
\end{abstract}

Keywords: Paracoccidioidomycosis. Fungal infection. Epidemiology.

\section{INTRODUCTION}

Paracoccidioidomycosis (PCM) is a systemic infection caused by the fungus Paracoccidioides brasiliensis ${ }^{1,2}$ and is considered one of the most important systemic mycoses in Latin America $^{3}$. The countries with the greatest number of cases are Brazil, Venezuela and Argentina. Brazil, which accounts for $80 \%$ of the cases, has a greater number of cases concentrated in its southeastern, southern and midwestern regions. Humans were considered to be the only host until recently, when the fungus was identified in other animals, such as the armadillo ${ }^{4,5}$.

The most common transmission mode is inhalation of the fungus, which then reaches the primary infection site and spreads to other tissues via the lymphatic system. Traumatic inoculation, in which the fungus settles on the skin or mucosa, can also occur ${ }^{6}$.

\footnotetext{
Address to: Dr. Gabriel de Deus Vieira. Dept ${ }^{0}$ de Medicina/Faculdade São Lucas. R. Alexandre Guimaraes 1927, Bairro Areal, 76804-373 Porto Velho, RO, Brasil. Phone: 5569 8491-6396

e-mail: gabrielvieira.mg@hotmail.com

Received 29 October 2013

Accepted 30 January 2014
}

Paracoccidioidal infection is more common between the first and second decades of life. However, progression to the systemic form is rare. Between the third and fifth decades of life, the disease is activated, causing the chronic form of PCM. Men, usually rural workers, are mainly affected, and poor hygiene, malnutrition, smoking and alcohol consumption, which are common habits in farmers, are considered to be risk factors for the manifestation of the disease?

An individual with PCM initially presents nonspecific symptoms such as cough, fever, weight loss and the presence of phlegm. However, the search for medical assistance is prompted by extrapulmonary lesions ${ }^{8,9}$. P. brasiliensis promotes pulmonary and extrapulmonary lesions, generating sequelae that limit daily activities and cause work disability. Therefore, PCM should be considered a public health problem ${ }^{10,11}$.

Some studies have shown the importance of PCM for the State of Rondônia. Court et al. ${ }^{12}$, in a study on dogs as vectors of the fungus in Monte Negro, noted that $54.8 \%$ of the dogs that were examined were positive for infection by the fungus, which suggests a high rate of infection in these animals. Forjaz et al. ${ }^{13}$, in their study of PCM in an indigenous population, noted that the disease was also present in the indigenous Suruí population.

In light of these findings, the present study evaluated the epidemiological profiles of PCM in the State of Rondônia, Brazil. Records for PCM in this state are rare in the literature, and this study is the largest casuistry of this disease in the Brazilian literature. 


\section{METHODS}

This is an epidemiological, descriptive, quantitative study of PCM cases diagnosed in patients who attended the public health system (Sistema Único de Saúde [SUS]) in Rondônia from 1997 to 2012. Official data and statistics provided by the State Agency for Health Surveillance of Rondônia (Agência Estadual de Vigilância Sanitária [AGEVISA]), the Notifiable Diseases Information System (BNDNS) and SINAN NET were used to enable a more thorough analysis of the current data on the disease. The variables that were studied included sex, age group, year of diagnosis, education level, profession, place of residence, diagnostic test, prior treatment, medication used, comorbidities and case progress.

The TABWIN (www.datasus.gov.br/tabwin) software was used to draw maps.

\section{RESULTS}

From January 1997 to December 2012, 2,163 cases of PCM were registered in Rondônia (Table 1). The annual incidence of the disease was analyzed in all 52 municipalities of the state. Among the 14 municipalities with the highest rates, 12 were located in the southeastern region; the exceptions were Machadinho do Oeste and Alvorada do Oeste. The municipalities with the highest rates were Pimenteiras do Oeste (39.1/100,000 people), Espigão do Oeste (37.4/100,000 people), Pimenta Bueno (20.8/100,000 people) and Primavera de Rondônia (20.2/100,000 people). The capital, Porto Velho, had a low incidence compared with the other municipalities in the state (1.6/100,000 people) (Figure 1).

The mean (SD) number of cases was $135.1( \pm 52.7)$ per year (Table 1). Regarding sex, $90.2 \%(1,952)$ and $9.8 \%$ (211) of cases were observed in men and women, respectively. The years with the highest and lowest incidences during the study period were 2003 and 2012, with $15.3(r f=0.1030)$ and $2.4(r f=0.0175)$ cases, respectively (Figure 2). The age range of the patients was 3-82 years, and the most common age group was $40-59$ years, which had 1,258 (58.2\%) cases, followed by $\geq 60$ years, which had 445 (20.6\%) cases. Regarding education, 404 (24.3\%) patients were illiterate, and 1,169 (70.4\%) had completed elementary school. Regarding professional activity, $82.7 \%(1,741)$ worked in some activity in the countryside. Regarding residence, $53.6 \%(1,161)$ and $46.4 \%(1,002)$ lived in urban and rural areas, respectively (Table 2).

Of the tests used for diagnosis, 899 (41.6\%) cases were diagnosed using direct mycological examination, 774 (35.8\%)

TABLE 1 - Number of cases, number of deaths, relative frequencies, mortality rates and percentages of deaths from paracoccidioidomycosis in Rondônia in 1997-2012.

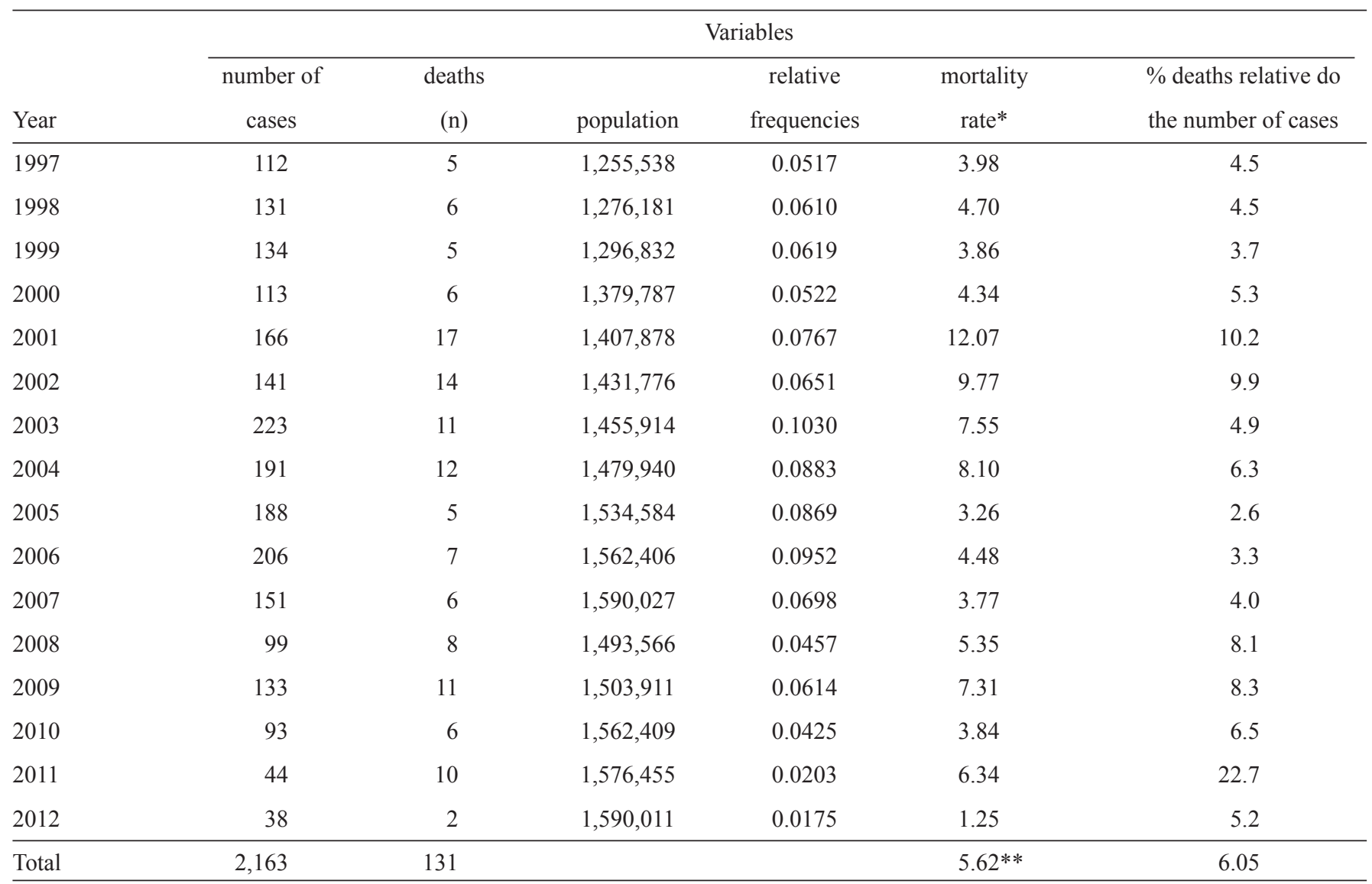

*Calculations based on 1,000,000 inhabitants; ** Mean mortality rate. Source: SINAN and SINAN NET. 


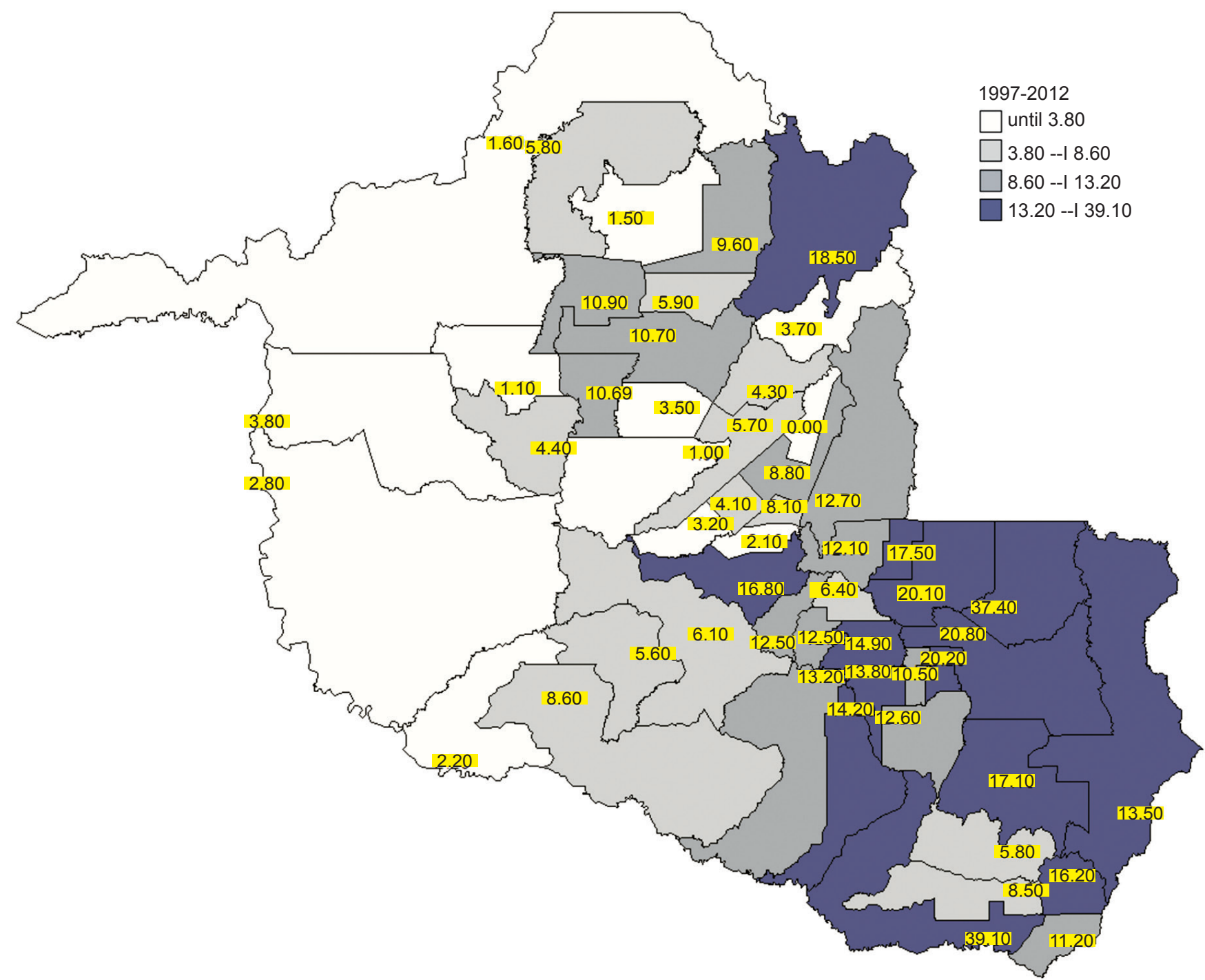

FIGURE 1 - Incidence of paracoccidioidomycosis cases by municipality in the State of Rondônia in 1997-2012 per 100,000 inhabitants/year. Source: SINAN and SINAN NET.

were diagnosed on the basis of clinical-epidemiological suspicion, 312 (14.4\%) were detected using histopathology, 114 (5.2\%) were detected using serology, and 64 (3\%) were detected using sputum culture. Regarding infectious and oncological comorbidities, $10(0.5 \%)$ patients had tuberculosis, $6(0.4 \%)$ had human immunodeficiency virus (HIV) infection, $1(0.05 \%)$ had cutaneous leishmaniasis, and $2(0.1 \%)$ were diagnosed with lung cancer.

Regarding treatment, the most commonly used drug was itraconazole, which was used in 1,771 (91.6\%) cases, followed by sulfamethoxazole in combination with trimethoprim in $85(4.4 \%)$ cases, ketoconazole in $32(1.7 \%)$ cases and other drugs in $45(2.3 \%)$ cases. Information on 230 of the cases was unavailable. Of the cases from 2009, $59(19.2 \%)$ patients had previously received treatment, and $22(7.1 \%)$ had discontinued treatment earlier. A total of 131 (6.05\%) patients died; the year with the highest mortality rate was 2001 (12.07 per 1,000,000 inhabitants), and the year with the highest percentage of deaths was $2011(22.7 \%)$ (Table 1).

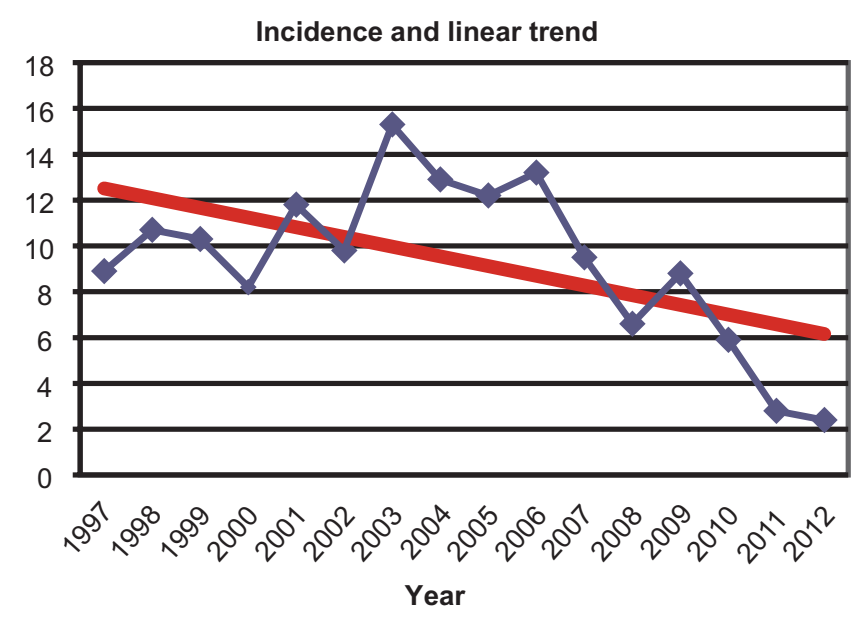

FIGURE 2 - Annual incidence and linear trend of paracoccidioidomycosis diagnoses in the State of Rondônia in 1997-2012 per 100,000 inhabitants/year. Source: SINAN and SINAN NET. 
TABLE 2 - Characteristics of paracoccidioidomycosis patients in Rondônia in 1997-2012.

\begin{tabular}{|c|c|c|c|}
\hline Variable & $\mathrm{n}$ & $\%$ & Missing* \\
\hline \multicolumn{4}{|l|}{ Age group (years) } \\
\hline$<14$ & 45 & 2.1 & \\
\hline $15-19$ & 10 & 0.5 & \\
\hline $20-39$ & 405 & 18.6 & \\
\hline $40-59$ & 1,258 & 58.2 & \\
\hline$\geq 60$ & 445 & 20.6 & \\
\hline Education level & & & 504 \\
\hline illiterate & 404 & 24.3 & \\
\hline basic schooling & 1,169 & 70.4 & \\
\hline high school & 81 & 4.9 & \\
\hline university degree & 5 & 0.4 & \\
\hline \multicolumn{4}{|l|}{ Area } \\
\hline urban & 1,161 & 53.6 & \\
\hline rural & 1,002 & 46.4 & \\
\hline Occupation & & & 58 \\
\hline rural activity & 1,741 & 82.7 & \\
\hline domestic & 100 & 4.7 & \\
\hline driver & 92 & 4.2 & \\
\hline construction & 55 & 2.6 & \\
\hline general services & 49 & 2.3 & \\
\hline commerce & 22 & 1 & \\
\hline others & 46 & 2.7 & \\
\hline
\end{tabular}

Prior treatment**

\begin{tabular}{lrr} 
yes & 59 & 19.2 \\
discontinued & 22 & 7.1 \\
\hline
\end{tabular}

\begin{tabular}{lrr}
\hline Case progress & \\
alive & 2,032 & 94 \\
dead & 131 & 6
\end{tabular}

*Missing data; **Data from 2009 onwards only. Source: SINAN and SINAN NET.

\section{DISCUSSION}

PCM is not included in the National List of Notifiable Diseases in Brazil. Therefore, cases are only registered in states where the disease has epidemiologically relevant rates ${ }^{14}$. Rondônia is one of the few Brazilian states where reporting the disease is mandatory because of its high number of cases ${ }^{15}$.

During the analyzed period, the mean annual incidence was $9.4 / 100,000$ people. This value is high compared with the estimated incidence in Brazil, which is 1 to $3 / 100,000$ people $^{16}$. This value can be explained by the State of Rondônia having high agricultural activity and possessing favorable climatic characteristics, such as abundant rain and forest wetlands ${ }^{17}$. The municipalities with the highest incidence rates were shown to be those located in the southeastern region of the State, which is the area in the state with the greatest agricultural development, including areas for raising livestock and planting soybeans, corn and coffee ${ }^{18}$.

The year 2003 had the highest number of cases, which might correspond to a period when health professionals in Rondônia were trained to improve the mandatory reporting of notifiable diseases ${ }^{18}$, thereby decreasing underreporting and the likelihood of reporting only severe cases.

With respect to the activities and/or professions that were associated with a risk of infection by the fungus, individuals performing activities related to the management of soil, such as agricultural activities, earth moving, soil preparation, gardening and transportation of produce, were the most frequently infected ${ }^{9}, 18$. Verli et al. ${ }^{9}$ found that $44.3 \%$ of PCM patients performed some type of farming activity, and other studies reported similar results ${ }^{19,20}$. Nevertheless, activities that are not risk factors for PCM do not preclude its diagnosis; in particular, activities on derelict land, gardens and leisure parks are not free from the risk of infection by the fungus ${ }^{21}$. The present results show that the most common occupations of the infected patients were those related to rural activities $(82.7 \%)$.

Regarding the area of residence, cases observed in urban (53.6\%) and rural (46.4\%) areas were nearly similar. According to Maluf et al. ${ }^{21}$, care must be taken when evaluating such results, and the peculiarities of small municipalities and districts must be taken into account because many individuals in these cities perform occupational or even leisurely rural activities that generally involve close contact with soil particles that are suspended in dust.

In this study, the predominance of male patients was evident, with $90.2 \%$ of the cases observed in men. Kamegasawa et al. ${ }^{22}$ studied 50 cases and also noted the predominance of male patients (73.9\%). Other studies also reported similar findings, e.g., Pedroso et al. ${ }^{10}$ reported the ratio of male to female patients to be $14: 1$. Although many women perform rural activities and are in contact with the soil, the frequency of cases in women was lower because of the protective action of estrogen against $P$. brasiliensis, i.e., estrogen inhibits the transformation of the infectious form of the fungus (i.e., mycelium) to the parasitic yeast form ${ }^{23}$.

PCM usually manifests in people older than 30 years and who may or may not have been in contact with the fungus in the first decades of $l i f e^{21}$; therefore, PCM is predominant in adult and elderly populations ${ }^{24,25}$. In their study of 43 PCM patients, Verli et al. ${ }^{9}$ showed that the age group with the highest prevalence was 40-59 years and that the disease was rarely present in children and adolescents. In the present study, the age groups with the highest prevalence were $40-59$ years $(58.2 \%)$ and $\geq 60$ years $(20.6 \%)$.

In Rondônia, the diagnostic or clinical suspicion tests that were frequently used for PCM included direct mycological 
examination (41.6\%), clinical epidemiology $(35.8 \%)$ and histopathology (14.4\%). Campos et al. ${ }^{26}$ reported that $65.9 \%$, $65.7 \%$ and $27.3 \%$ of patients were diagnosed using direct mycological examination, sputum culture and histopathology, respectively. Radiological changes are of the utmost importance in cases with clinical and epidemiological suspicion of P. brasiliensis infection ${ }^{8}$. Gomes et al. ${ }^{8}$ observed several radiological changes in patients with PCM: $74.5 \%$ of patients presented regional lymphadenopathy, and $65.3 \%$ presented pulmonary lesions, with $8 \%$ having comorbid tuberculosis.

According to Fortes et al. ${ }^{1}, P$. brasiliensis infection is not closely related to host immunodeficiency. However, cases associated with HIV infection, cancer and organ transplantation have been reported. A few such cases were observed in the present study, and the infectious and neoplastic comorbidities included tuberculosis (10), HIV infection (6), lung cancer (2) and cutaneous leishmaniasis (1). Special attention should be paid to HIV because the number of cases of infected individuals older than 50 years of age has increased over the last 10 years and is now reaching $14.3 \%$ of the HIV-infected population ${ }^{27}$. Campos et al. ${ }^{26}$ reported the presence of HIV infection in $0.8 \%$ of patients with PCM, and HIV infection may be a factor that interferes with the host-fungus relationship.

Even before the National PCM Consensus in 2006 advocated the use of itraconazole, this drug had been adopted as the drug of choice for the treatment of PCM in Rondônia because it was available from the Primary Health Care Network. ${ }^{28}$ Among the medications that were administered, itraconazole was the most commonly used drug (91.6\%), followed by sulfamethoxazoletrimethoprim $(4.4 \%)$, which was generally used in children younger than 10 years of age, pregnant women, patients with neurological manifestations and patients using medications for diseases such as tuberculosis and leprosy. In a study conducted in a stomatology clinic, 27 (57.5\%), $12(25.5 \%)$ and $3(6.4 \%)$ patients were administered sulfadiazine, ketoconazole and itraconazole, respectively9.

According to Coutinho et al. ${ }^{29}, \mathrm{PCM}$ is the systemic mycosis with the highest mortality rate in Brazil. Furthermore, Rondônia is the state with the highest percentage of fatal cases in the northern region and was the Brazilian state with the second highest mortality rate between 1980 and 1995, with a coefficient of mean mortality of 3.65/1,000,000 people. In Rondônia from 1997 to 2012, we noted that the coefficient of mean mortality was $5.59 / 1,000,000$ people. The present study revealed that the fewest number of deaths during the study period occurred in 2012, with 5.2\% of patients dying. In 2001 and 2002, a lack of drug distribution by the public health service occurred because of a change in the coordination of the PCM program in Rondônia ${ }^{18}$, resulting in high percentages of deaths relative to the number of cases in these years $(10.2 \%$ and $9.9 \%$, respectively).

In conclusion, the number of PCM cases in Rondônia has decreased in recent years. This decrease is most likely due to improvements in disease control and prevention systems by the public health agencies of the state, including the actions of health education, transmitting information about the disease to people and training health professionals, and/or the increased rural exodus in recent decades, which has reduced the number of individuals who come in direct contact with the soil while working. Some measures can be used to control fungus infections, such as teaching the correct use of appropriate masks, treating patients properly and as early as possible to avoid the formation of sequelae and ensuring that doctors include PCM in the differential diagnosis of respiratory diseases ${ }^{14,30,31}$. The disease predominantly affects men, those older than 40 years, those in occupations related to agriculture and those with little or no education.

\section{ACKNOWLEDGMENTS}

The authors thank Rui Rafael Durlacher for his advice and assistance in the interpretation of the epidemiological data.

\section{CONFLICT OF INTEREST}

The authors declare that there is no conflict of interest.

\section{REFERENCES}

1. Fortes MRP, Miot HÁ, Kurokawa CS, Marques MEA, Marques MSA. Immunology of paracoccidioidomycosis. An Bras Dermatol 2011; 86:516-525.

2. Ramos ESM, Saraiva LDO. Paracoccidioidomycosis. Dermatol Clin 2008; 26:257-269.

3. Rassi TNO, Passos RRB, Kumagai KM, Soranz Filho JR, Freitas JAH. Chronical and multifocal paracoccidioidomycosis having the lid involvement as the first sign: case report. Arq Bras Oftalmol 2009; $72: 822-825$.

4. Corredor GG, Castaño JH, Peralta LA, Díez S, Arango M, McEwen J, et al. Isolation of Paracoccidioides brasiliensis from the nine-banded armadillo Dasypus novemcinctus, in an endemic area for paracoccidioidomycosis in Colombia. Revta Iberoam Micol 1999; 16:216-220.

5. Bagagli E, Sano A, Coelho KI, Alquati S, Miyaji M, Camargo ZP, et al. Isolation of Paracoccidioides brasiliensis from armadillos (Dasypus novemcinctus) captured in an area of paracoccidioidomycosis. Am J Trop Med Hyg 1998; 58:505-512.

6. Santos WA, Silva BM, Passos ED, Zandonade E, Falqueto A. Association between smoking and paracoccidioidomycosis: a case-control study in the State of Espírito Santo, Brazil. Cad Saúde Pública 2003; 19:245-253.

7. Silva-Vergara ML, Martinez R, Camargo ZP, Malta MH, Maffei CM, Chadu JB. Isolation of Paracoccidioides brasiliensis from armadillos (Dasypus novemcinctus) in an area where the fungus was recently isolated from soil. Med Mycol 2000; 38:193-199.

8. Gomes E, Wingeter MA, Svidzinski TIE. Clinical-radiological dissociation in lung manifestations of paracoccidioidomycosis. Rev Soc Bras Med Trop 2008; 41:454-458.

9. Verli FD, Marinho AS, Souza SC, Figueiredo MAS, Yurgel LS. Clinicalepidemiologic profile of paracoccidioidomycosis at the Stomatology Department of São Lucas Hospital, Pontificia Universidade Católica of Rio Grande do Sul. Rev Soc Bras Med Trop 2005; 38:234-237.

10. Pedroso VSP, Vilela MC,Pedroso ERP,Teixeira AL.Paracoccidioidomycosis compromising the central nervous system: a systematic review of the literature. Rev Soc Bras Med Trop 2009; 42:691-697.

11. Pereira PMR, Akel PBM, Lima LLL, Kimura EM, Jalkh AP. Multifocal paracoccidioidomycosis: a diagnostic challenge due to late cutaneous manifestation. An Bras Dermatol 2011; 86:149-152. 
12. Corte AC, Gennari SM, Labruna MB, Camargo LMA, Itano EN, Freire RL, et al. Paracoccidioides brasiliensis infection in dogs from Western Brazilian Amazon. Pesq Vet Bras 2012; 32:649-652.

13. Forjaz MHH, Fischman O, Camargo ZP, Vieira Filho JPB, Colombo AL. Paracoccidioidomycosis in Amerindian populations of the Brazilian Suruí tribe: a clinical and laboratory study of two cases. Rev Soc Bras Med Trop 1999; 32:571-575.

14. Ministério da Saúde. Guia de Vigilância Epidemiológica CAD. $7^{\mathrm{a}}$ ed. Brasília/DF: Ministério da Saúde; 2009.

15. Durlacher RR, Lima SMD. Situação da Paracoccidioidomicose em Rondônia. Anais do XXXIX Congresso da Sociedade Brasileira de Medicina Tropical. 2003; p.35-36.

16. Wanke B, Londero AT. Epidemiology and paracoccidioidomycosis infection. In: Franco M, Lacaz CS, Restrepo-Moreno A, del Negro G, editors. Paracoccidioidomycosis. Boca Raton: CRC Press; 1994. p. 109-120.

17. Matias F. Pioneiros: Ocupação humana e trajetória política de Rondônia. Porto Velho: Maia; 1997.

18. Lima SMD.Análise da Situação Epidemiológica da Paracoccidioidomicose em Rondônia 1997 a 2008 - Brasil. [Masters Thesis]. [Rondônia]: Universidade Federal de Rondônia; 2010.

19. Blotta MHSL, Mamoni RL, Oliveira SJ, Nouér SA, Papaiordanou PMO, Gouveia A, et al. Endemic regions of paracoccidioidomycosis in Brazil: a clinical and epidemiologic study of 584 cases in the southeast region. Am J Trop Med Hyg 1999; 61:390-394.

20. Paniago AM, Aguiar JI, Aguiar ES, Cunha RV, Pereira GROL, Londero AT, et al. Paracoccidioidomycosis: a clinical and epidemiological study of 422 cases observed in Mato Grosso do Sul. Rev Soc Bras Med Trop 2003; $36: 455-459$

21. Maluf MLF, Pereira SRC, Takahachi G, Svidzinski TIE. Prevalence of paracoccidioidomycosis infection determined by sorologic test in donors' blood in the Northwest of Paraná, Brazil. Rev Soc Bras Med Trop 2003; 36:11-16.

22. Kamegasawa A, Silva MRBM, Franco M, Heimbeck FJ. Ocular paracoccidioidomycosis: report of two cases and review of literature. Arq Bras Oftalmol 1988; 51:183-185.

23. Restreppo AM, Salazar ME, Cano LE. Estrogens inhibit myceliumto-yeast transformation in the fungus Paracoccidioides brasiliensis: Implications for resistance of females to paracoccioidomycosis. Infect Immun 1984; 346-353.

24. Benard G. An overview of the immunopathology of human paracoccidioidomycosis. Mycopathologia 2008; 165:209-221.

25. Zaitz C, Ruiz LRB, Framil VMS. Paracoccidioidomicose: Diagnóstico e Tratamento. Manual de Conduta. JSBD 2006; 10:191-196.

26. Campos MVS, Penna GO, Castro CN, Moraes MAP, Ferreira MS, Santos JB. Paracoccidioidomycosis at Brasilia's University Hospital. Rev Soc Bras Med Trop 2008; 41:169-172.

27. Vieira GD, Alves TC, Sousa CM. Epidemiological analysis of Aids in elderly in the state of Rondonia, Western Amazon. DST - J Bras Doenças Sex Transm 2012; 24:49-52.

28. Secretaria Estadual de Desenvolvimento Ambiental de Rondônia. Boletim no 7. 2009

29. Coutinho ZF, Silva D, Lazéra M, Petri V, Oliveira RMO, Sabroza PC, et al. Paracoccidioidomycosis mortality in Brazil (1980-1995). Cad Saude Publica 2002; 18:1441-1454.

30. Marques SA. Paracoccidioidomycosis: Epidemiological, Clinical and Treatment up-date. An Bras Dermatol 2003; 78:135-150.

31. Shikanai-Yasuda MA, Telles Filho FQ, Mendes RP, Colombo AL, Moretti ML, Grupo de Consultores do Consenso em Paracoccidioidomicose. Guideliness in paracoccidioidomycosis. Rev Soc Bras Med Trop 2006; 39:297-310. 